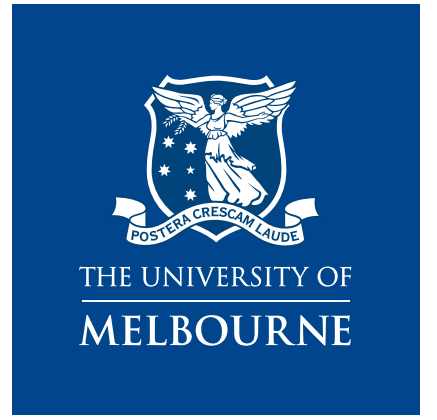

\title{
A DAY IN THE LIFE OF A STUDENT
}

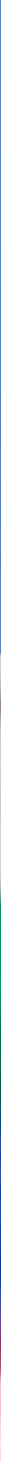

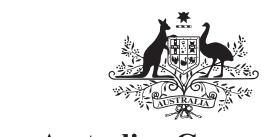

Australian Government Australian Research Council
DLR Group

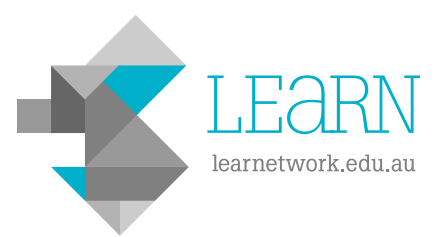

INNOVATIVE LEARNING ENVIRONMENTS AND TEACHER CHANGE
A 2016-2019 ARC LINKAGE PROJECT 
CONTENTS

OVERVIEW

FACILITATOR'S CHECKLIST

STEP-BY-STEP GUIDE

RESOURCES 


\section{WHAT IS IT?}

A Day in the Life of a Student workshop is a design thinking workshop developed by DLR Group (an integrated design firm) and adapted by the Innovative Learning Environment and Teacher Change project at the University of Melbourne, Australia. The activities involve educators mapping out how one student spends his/her day in school and building a model of the learning environment based on this one student. With an emphasis on the visual learning that comes from modelling experiences, this workshop helps participants develop student-improvement focused practices in innovative learning environments.

\section{HOW DID WE COME UP WITH IT?}

A Day in the Life of a Student workshop was developed using design thinking principles that engage participants directly with ambiguous prompts yet tangible materials. These workshops usually move participants between divergent, expansive thinking exercises and convergent, solution-oriented modes of thinking. Adapting a persona tool used in human-centred design to profile a potential student helps participants empathise with how that individual views learning, providing insights on his/her learning experience. The design-thinking approach also takes into account the ever-changing perspectives of the diverse individuals involved through open collaboration.
The workshop begins with the assumption that teachers can create or adjust their learning spaces to more closely align with and accommodate the particular needs of their students by understanding the different levels of ability and learning requirements of individual students. By understanding what and how a student learns and his or her preferred mode of learning, teachers can develop personalised instruction in appropriate learning spaces so that all students can learn effectively.

\section{HOW WILL IT BENEFIT YOU?}

The design thinking workshop is about teachers making a difference by using an intentional process in order to get to new, relevant solutions that create positive impact. Specifically, information gathered from the workshops can provide teachers and school leaders an understanding of:

- how learners with diverse needs, motivations, expectations, goals, and challenges learn in innovative learning spaces;

- how to adjust teaching and learning approaches to accommodate each student's learning needs to achieve maximum growth as a learner; and

- strategies and tools to develop and apply differentiated instructional designs in their learning spaces.

\section{WHAT DOES SUCCESS LOOK LIKE?}

Teachers come away from the workshop with a shared understanding that their class is composed of diverse learners who differ not only culturally and linguistically but also in their cognitive abilities, cultural background, prior knowledge, and learning preferences. The workshop is collaborative in nature, consequently strategies and tools emerge from teachers' collective knowledge and from multiple perspectives. This knowledge enables teachers to apply the concept of differentiated learning to practice by creating opportunities for their students to use the learning space in ways that are effective and meet their individual needs.

\section{WHERE CAN I GET MORE INFORMATION?}

For more information about the workshop, please see:

www.dlrgroup.com and www.iletc.com 


\section{FACILITATOR'S \\ CHECKLIST}

\section{TIME}

Allow a minimum of two hours for this workshop.

\section{WORKSHOP VENUE}

Prepare an area that can accommodate whole group interaction as well as tables and chairs for small group collaboration of three to five participants during the activity.

\section{PARTICIPANTS}

Participants are organised into groups of three to five, preferably grouping individuals who are currently not working together, for example across year levels, disciplines etc, or have not met before. It is recommended to have a maximum of 20 participants per facilitator.

\section{MATERIALS TO PURCHASE}

- Art and craft materials such as wooden sticks, pipe cleaners, foam pieces, etc.

- Lego blocks

- Pens

\section{PREPARATION}

\begin{tabular}{|l|l|l|l|}
\hline Code & Item ${ }^{1}$ & Format/Preparation & Quantity \\
\hline DL01 & Student Persona & A4 single-sided print & One persona per group \\
\hline DL02 & $\begin{array}{l}\text { A Day in the Life of a Student } \\
\text { Board }\end{array}$ & A3 single-sided print & One per group \\
\hline DL03 & Activity Cards & A4 single-sided, cut to size & Two or three sets per group \\
\hline DL04 & Definitions and Examples of & A4 single-sided print & One per person \\
\hline DL05 & Action Plan & A4 single-sided print & One per person (depending on aims) \\
\hline DL06 & Arts and craft materials & To purchase & One set per group \\
\hline DL08 & Lego blocks & To purchase & One set per group \\
\hline DL09 & Pens & To purchase & One per person \\
\hline
\end{tabular}

${ }^{1}$ The resources are (refer to codes on each resource) supplied at 1:1 scale and should be printed at $100 \%$ of the original page size. The 'Choose paper source by PDF page size' on PC and 'Scale to fit paper size' on OSX in Adobe Acrobat will automatically print multiple page sizes automatically. For more information, please visit https://helpx.adobe.com/acrobat/kb/print-mixed-page-sizes-acrobat.html 


\section{STEP-BY-STEP GUIDE}

As the facilitator, think of what you would like your participants to get out of this. It could be one or a combination of objectives including: an understanding of how learners with diverse needs, motivations, expectations, goals, and challenges learn in innovative learning spaces; how to adjust teaching and learning approaches to accommodate each student's learning needs to achieve maximum growth as a learner; or developing strategies and tools to develop and apply differentiated instructional designs in particular learning spaces.

The following steps provide a 'script' that you could follow when running the workshop. It also provides the recommended time as well as the required resources for each step. You can amend to suit the audience and/or objective that you have developed prior to the workshop.

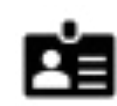

\section{BEFORE THE WORKSHOP}

\author{
[10 mins]
}

DL01, DL02, DL03, DL04, DL09

» Decide your overall aims for the workshop - what you would like participants to get out of it.

» Distribute and lay out one set of the workshop materials (DL01, DL02, DL03, DL04) and pens (DL09) on the centre of each table/group.

»Welcome participants and direct them to their groups/tables.

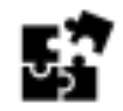

STEP 1: DISCOVER

\author{
[15 mins] \\ DL01, DL09
}

We are going to imagine how different students experience learning by spending a day in their shoes. In groups of three to five members, select one student persona and develop a profile of their learning preferences, goals and values. When thinking of your student, think of those that perhaps struggle in the current system and ensure a variety of experiences are reflected. Brainstorm with your group how that learner may best experience learning.

8 Discussion prompts:

»What are the different kinds of activities that this student prefers based on his/her preferences and goals?

» How do you think this student would like to manage his/her day?

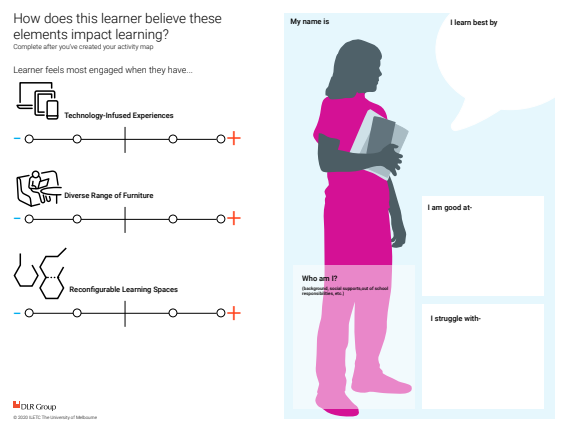

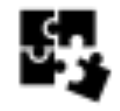

\section{STEP 2: REFLECT}

\author{
[30 mins] \\ DL01, DL02, DL03, DL04, DL09
}

Reflect on how you want your assigned student to spend their day and then create a 'map' of a day in the life of that student, by choosing from the range of learning activities provided. Blank space on the cards can be utilized to sketch what the learning experience may look like, what group sizes are desired, and how the environment may support it. Feel free to use the blank cards for additional activities. Iterate and change your map as needed, paying attention to the predominant learning activities. The definitions of learning activities and sample maps are illustrated in DL04.

Discussion prompts:

"What are the different kinds of activities that will help this student learn effectively?

»What are the valuable experiences I want this student to have?

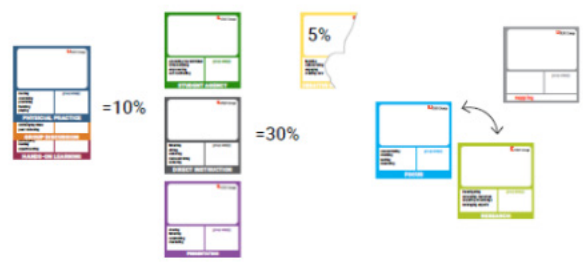




\section{$s$}

\section{STEP 3: IDEATE}

\section{[45 mins]}

\section{DL06, DL07}

Using the materials provided, develop a learning space/floor plan based on the desired learning activities of that student. Spend 30 minutes on this activity then another 15 minutes to share with the whole group your map and the design of your learning space. Take this time to observe similarities and differences.

8 Discussion prompts:

» What were some commonalities and differences in the learning space designs?

» How does the 'shape' and affordances of the learning environments differ?

»What elements of the learning space improves the experience of your student?

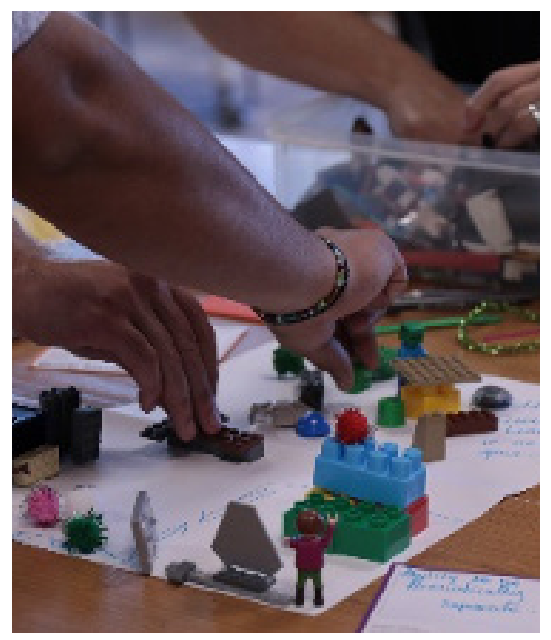

\section{sin}

STEP 4: EVOLVE

\author{
[20 mins] \\ DL05, DL09
}

Individually, think of one component of your teaching practice and the learning space that you can change. Develop an action plan that includes timelines, resources required and desired outcomes.

Q Tip for facilitators:

» Distribute the Action Plan (DL05) to participants. Depending on the aims you developed prior to the workshop, this could be an individual or group activity.

8 Discussion prompts:

"What resources do you need? What are some of the challenges?

"What does success look like?

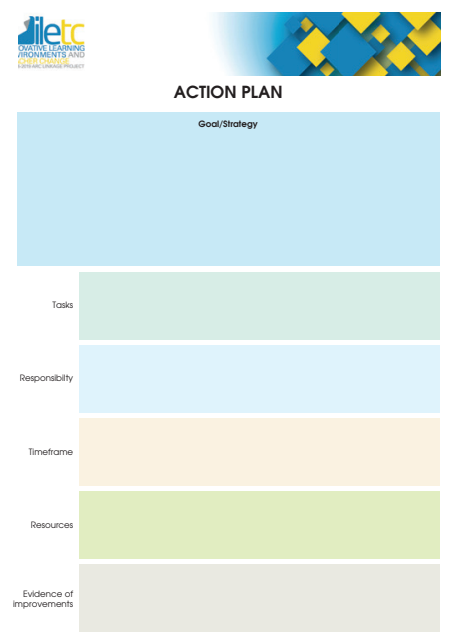




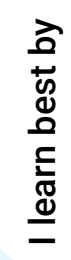
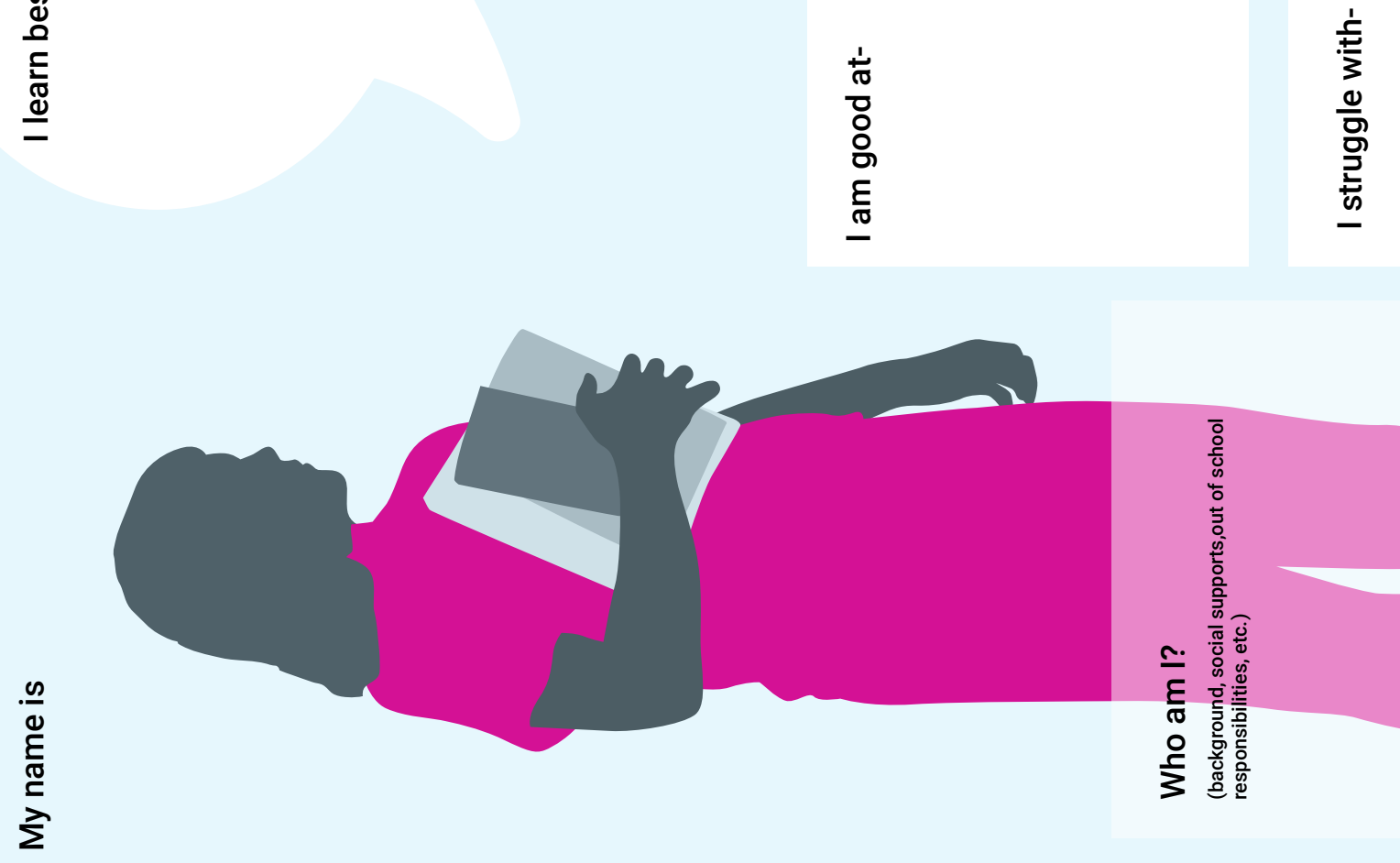

$\frac{1}{2}$

$\stackrel{0}{\Perp}$

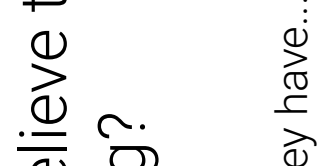
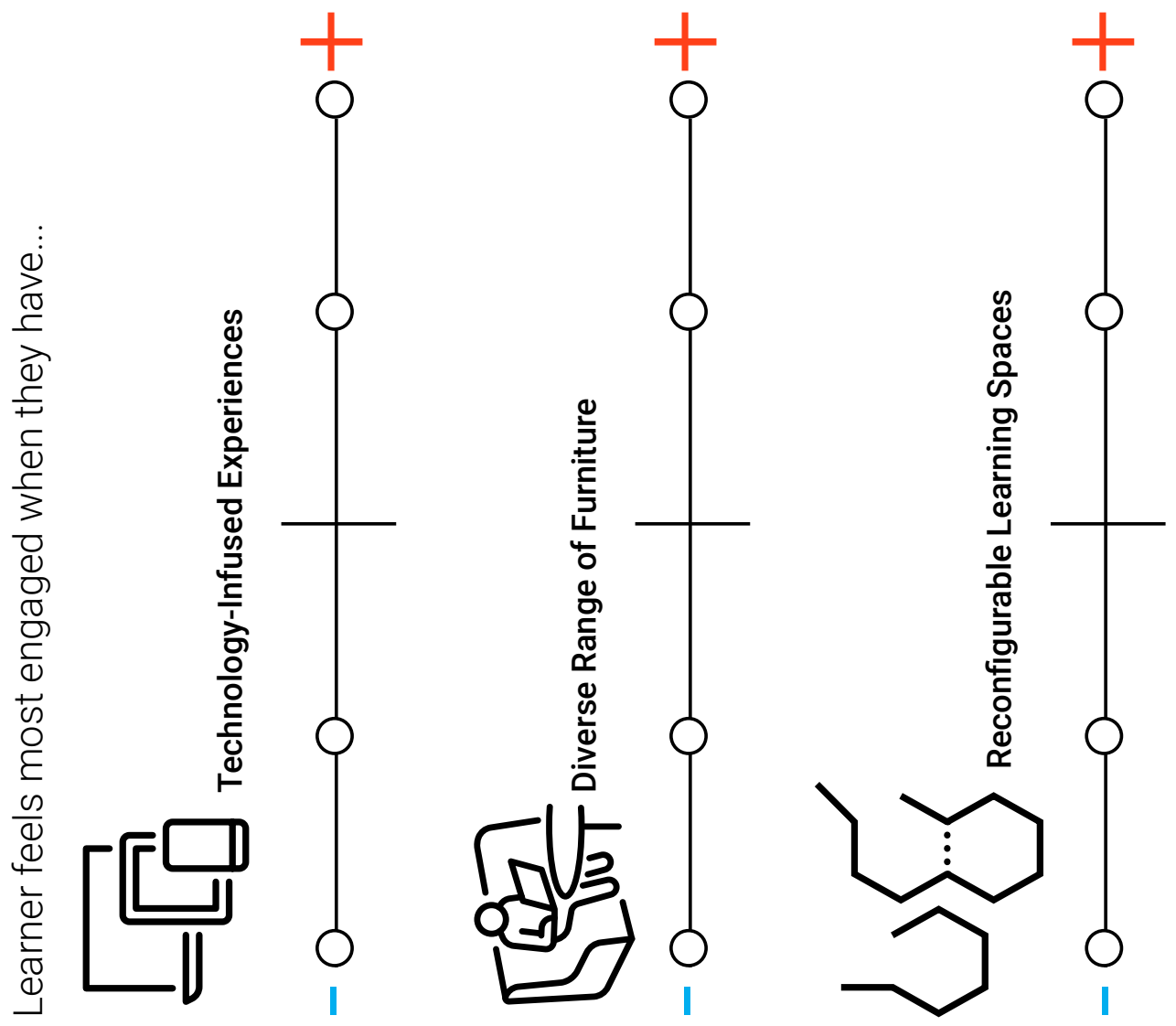

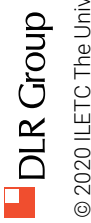




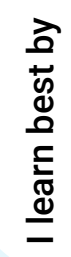

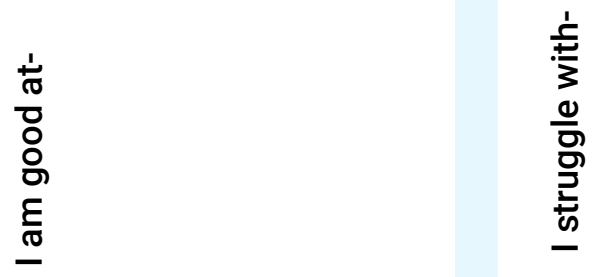

$\frac{00}{0}$
$\frac{E}{0}$
$\stackrel{\Sigma}{\Sigma}$
$\stackrel{Z}{Z}$

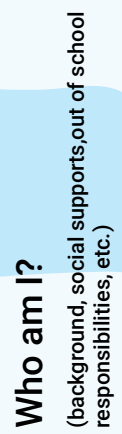

(1)

$\stackrel{\text { (1) }}{ \pm}$

(1) त.
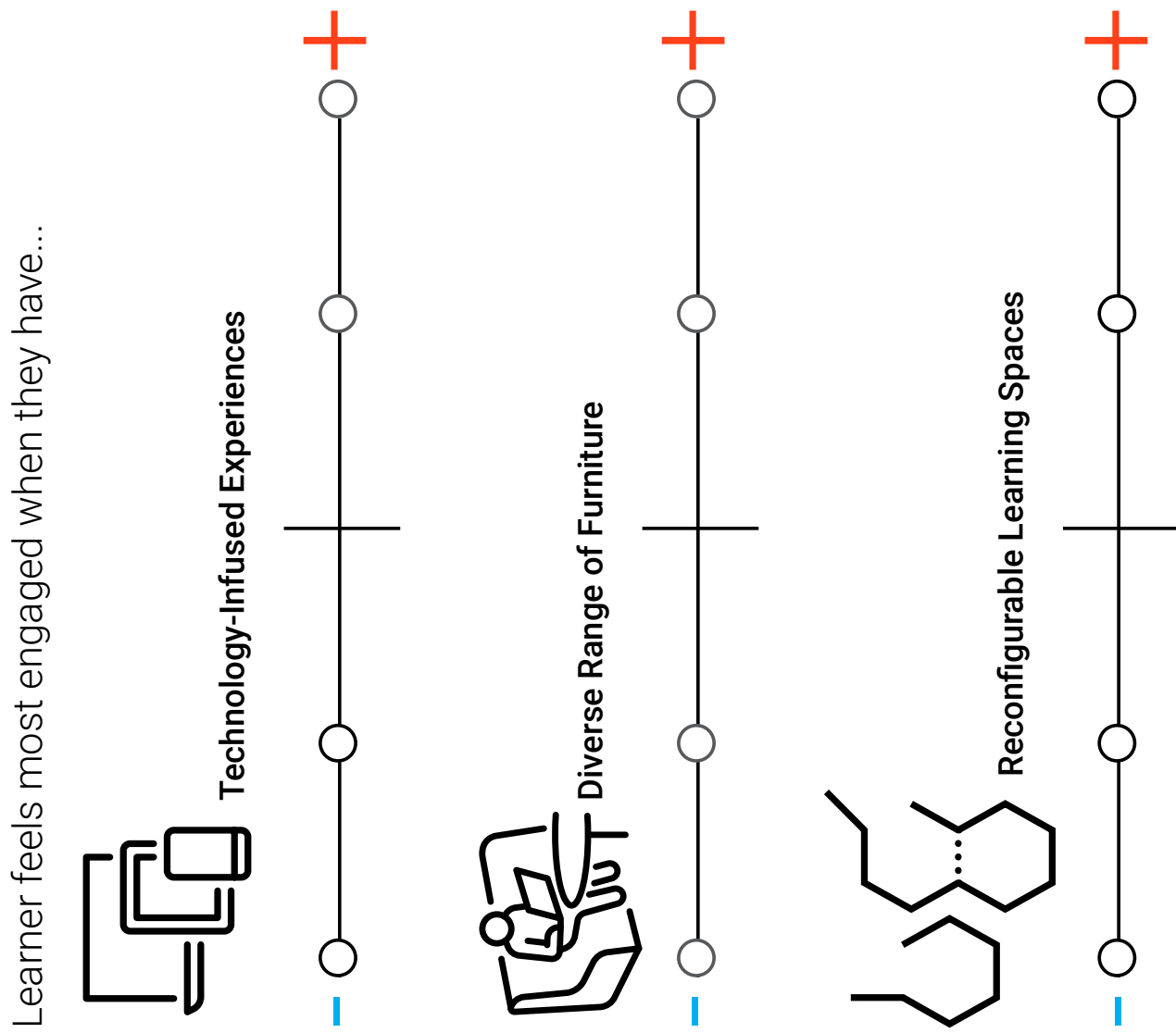

$\frac{0}{3}$
$\frac{0}{3}$
$\frac{\alpha}{1}$ 

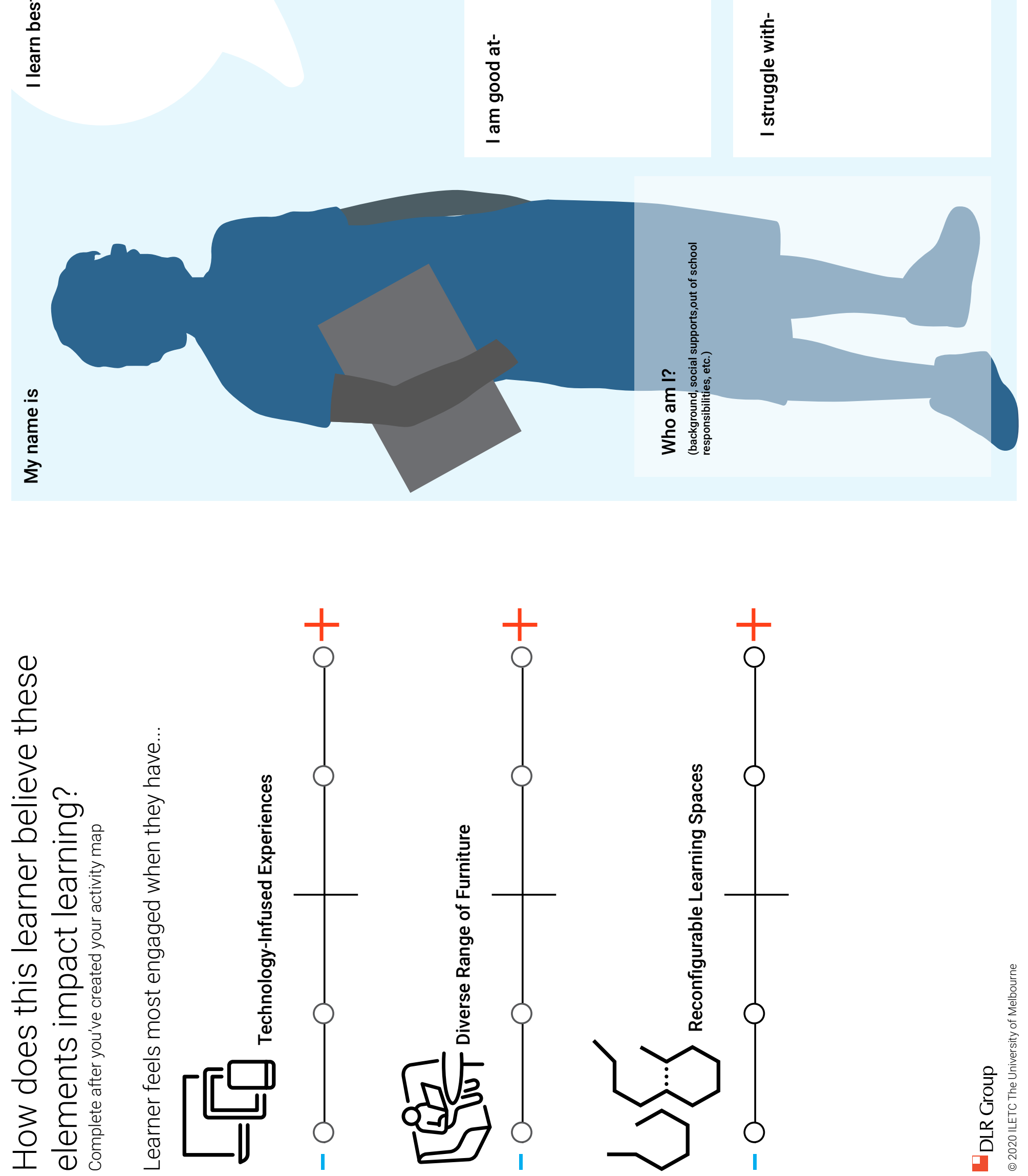

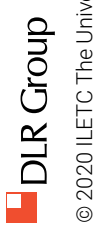



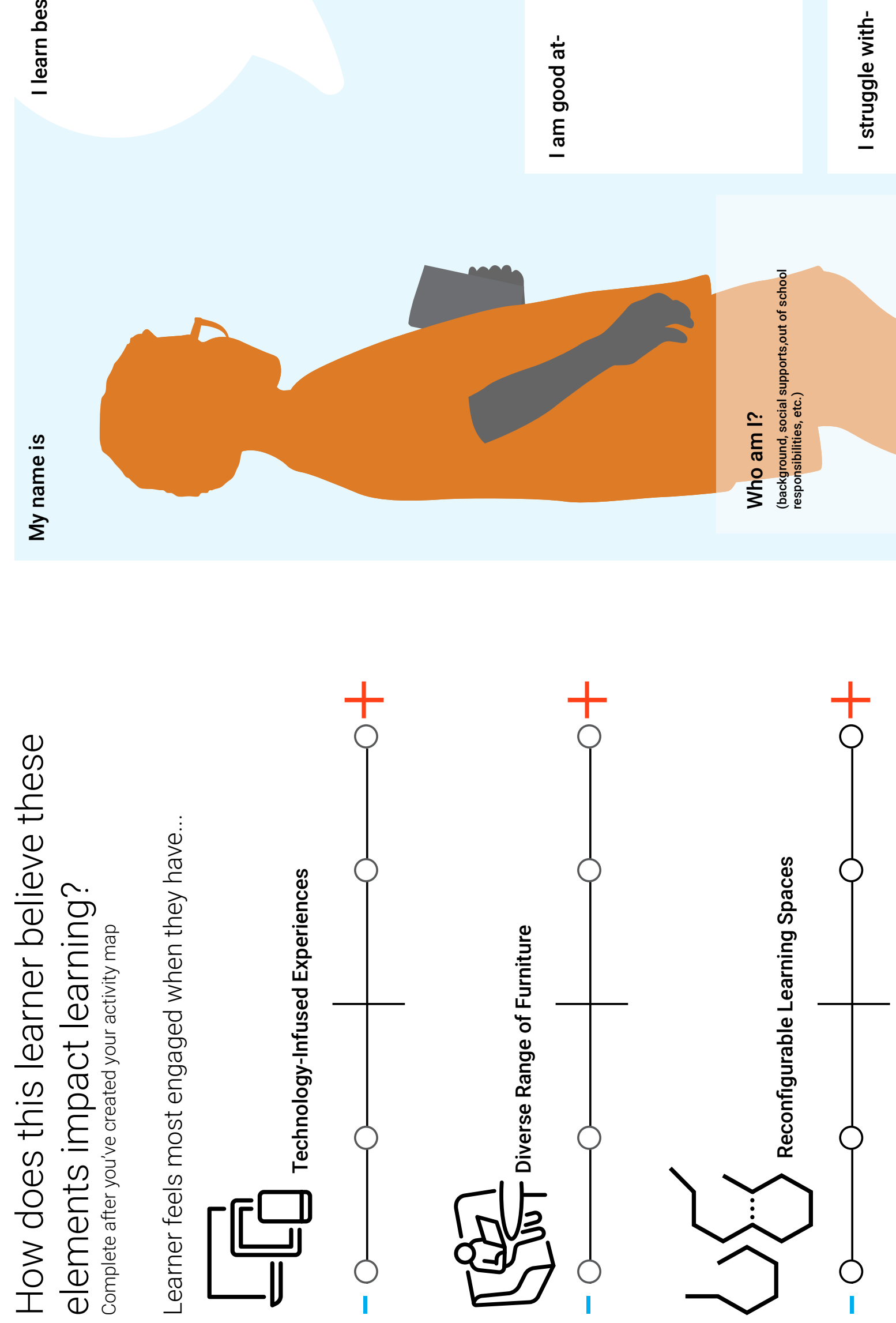

言 


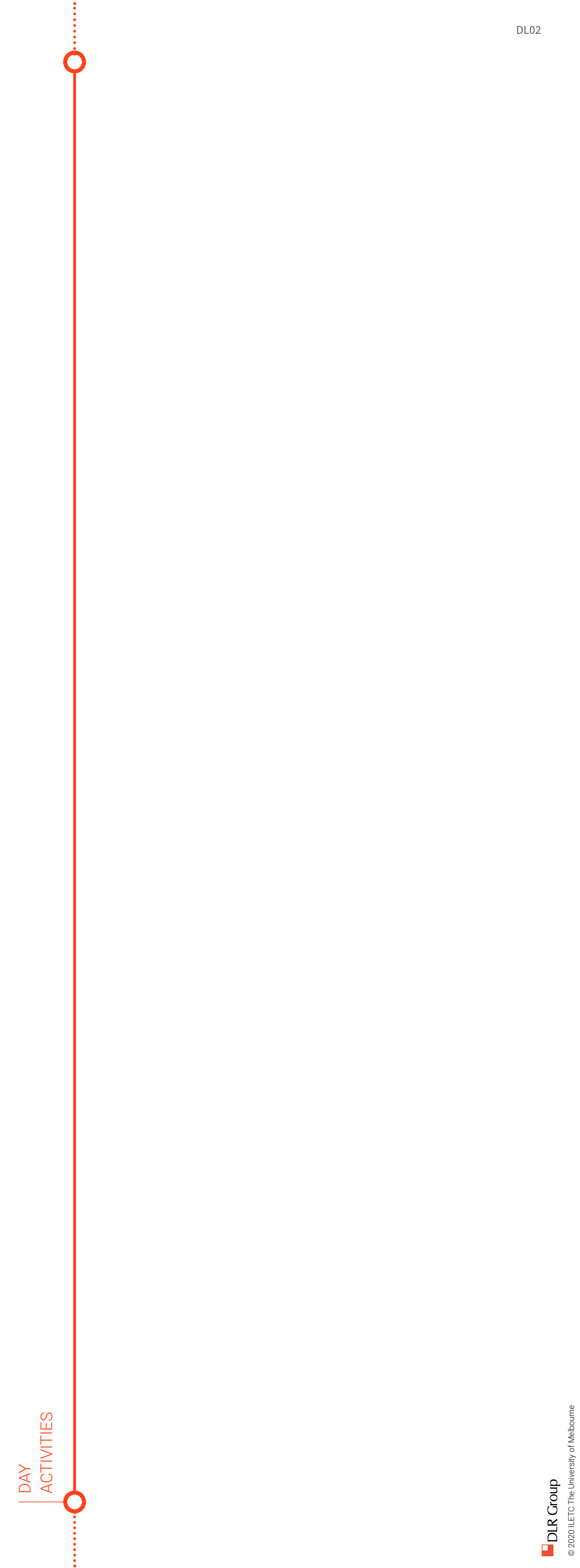



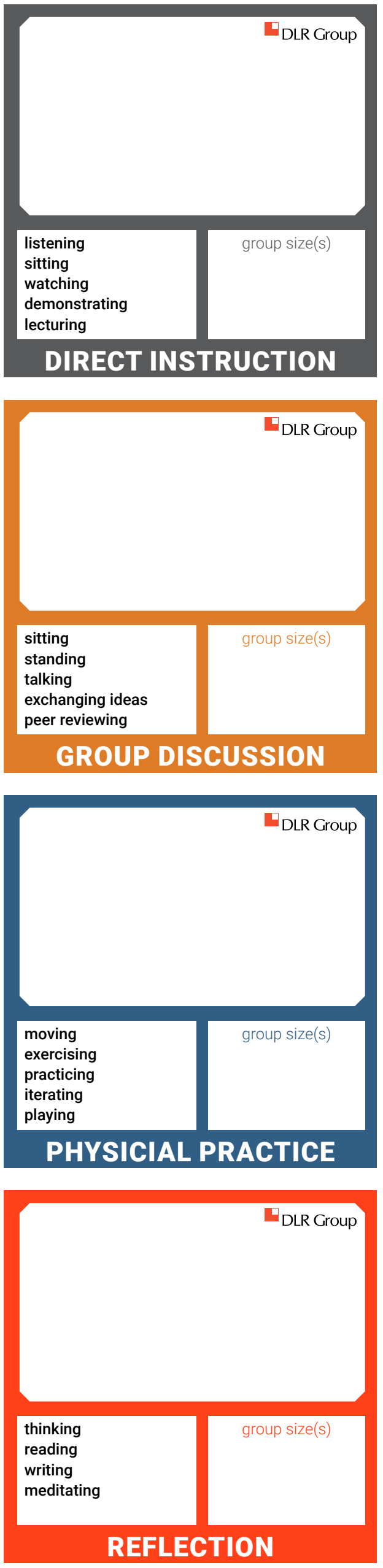
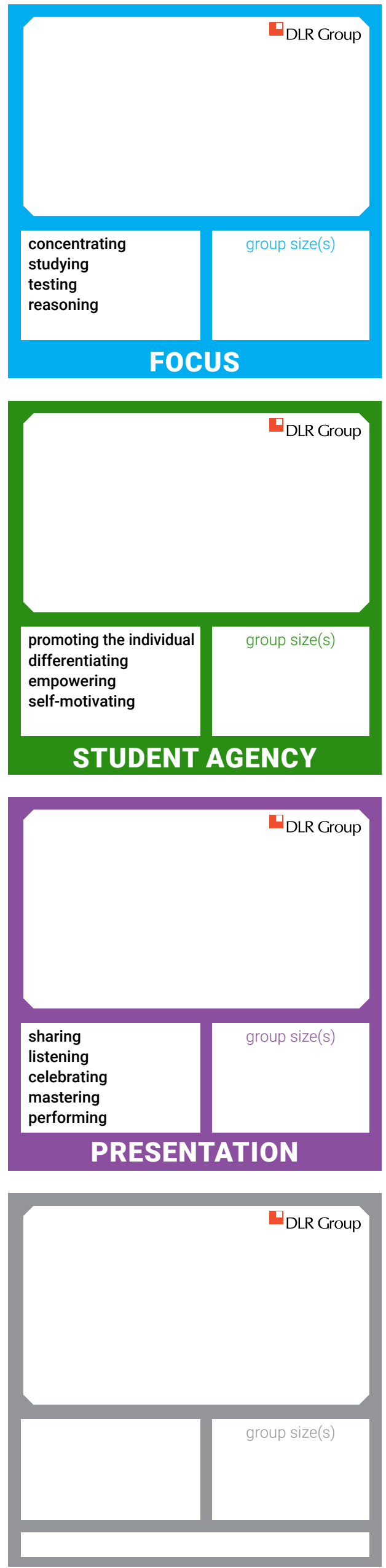

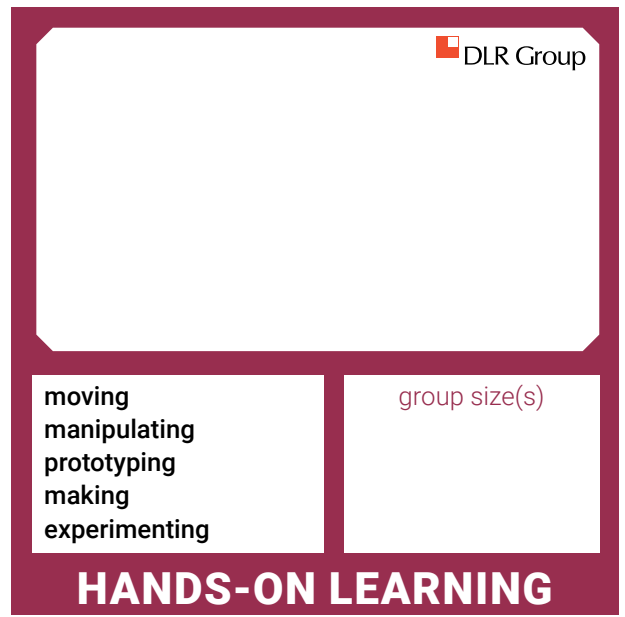

${ }^{\square}$ DLR Group

iterating

collaborating

engaging

creating new
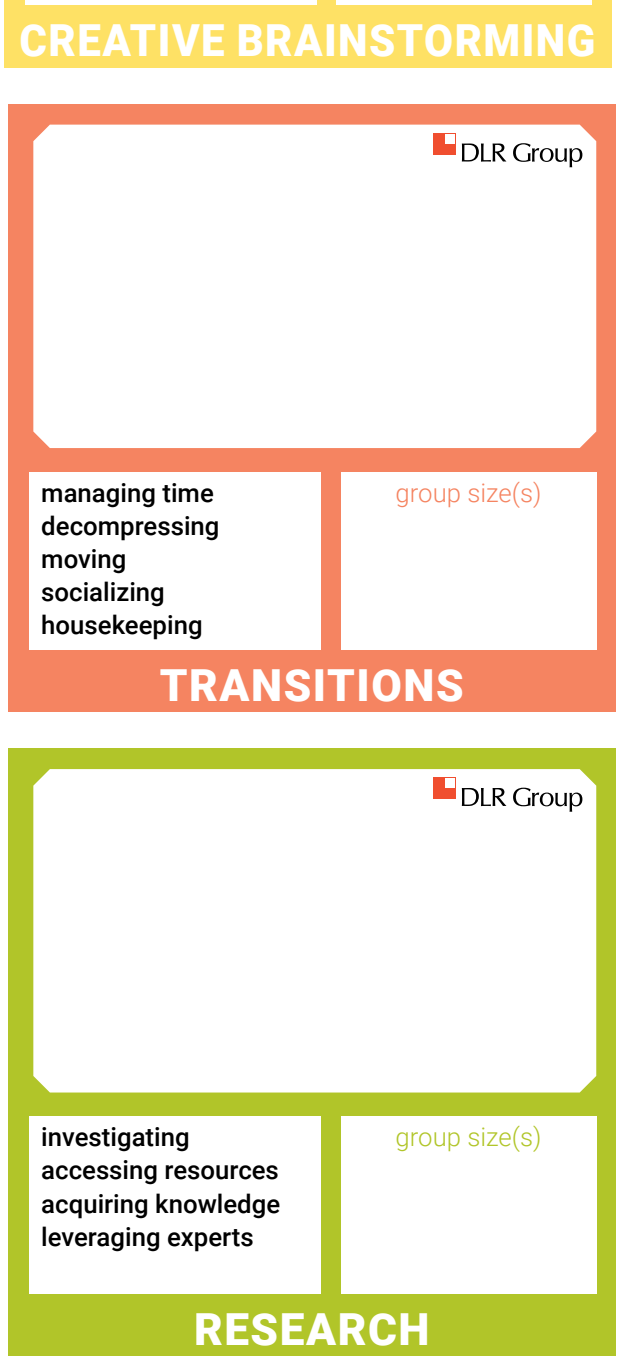

\section{DLR Group}



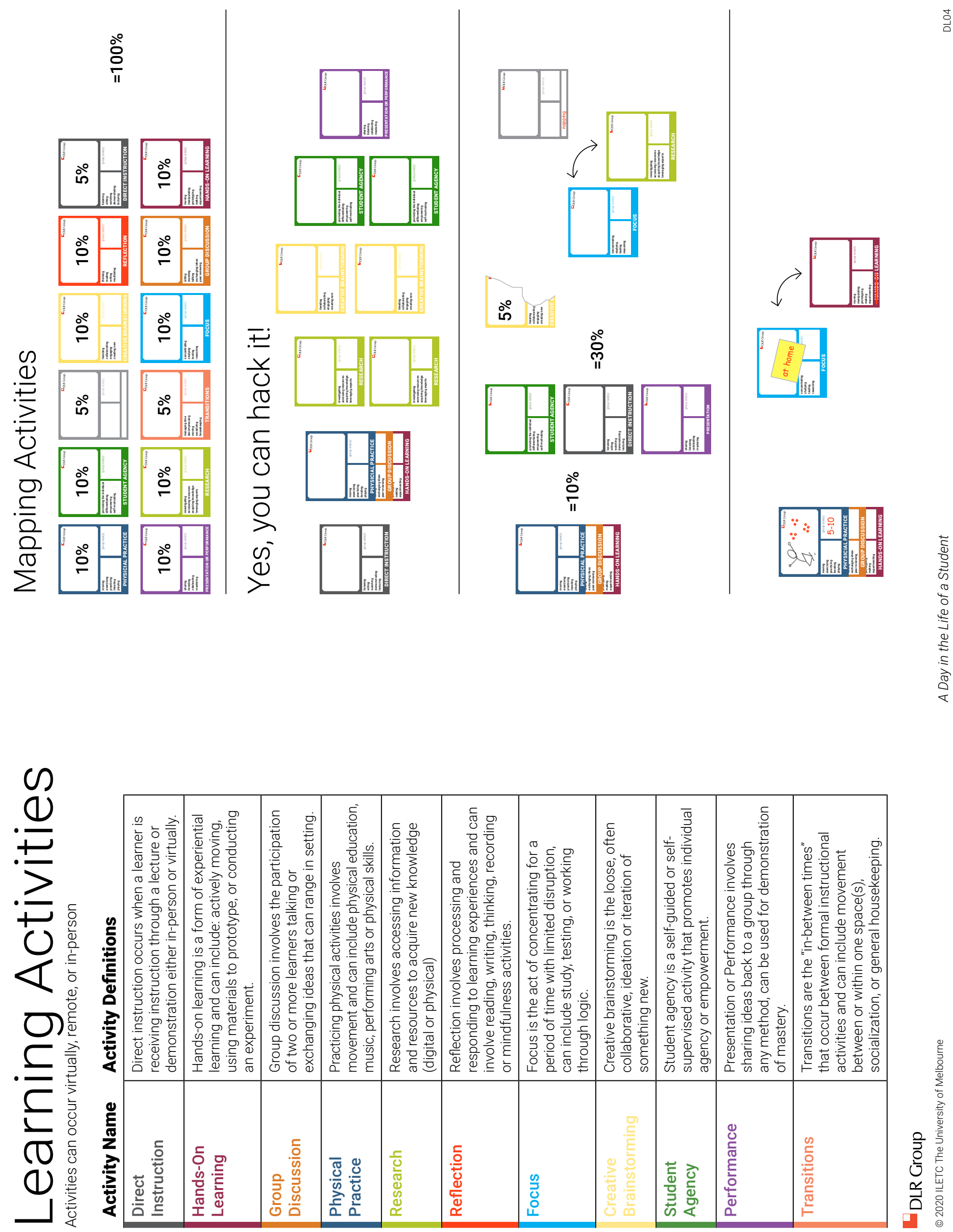


\title{
ACTION PLAN
}

\author{
Goal/Strategy
}

Tasks

Responsibilty

Timeframe

Resources

Evidence of improvements 
iletc.com.au 


\section{University Library}

\section{- M M I N E R VA A gateway to Melbourne's research publications}

Minerva Access is the Institutional Repository of The University of Melbourne

Author/s:

Mahat, M;Imms, W

Title:

A Day in the Life of a Student: Facilitator Guide

Date:

2020-12-21

Citation:

Mahat, M. \& Imms, W. (2020). A Day in the Life of a Student: Facilitator Guide. Melbourne Graduate School of Education, The University of Melbourne.

Persistent Link:

http://hdl.handle.net/11343/256332 